\title{
SOURCES AND VARIABILITY OF NON-METHANE HYDROCARBONS IN THE EASTERN MEDITERRANEAN
}

\author{
C. ARSENE ${ }^{1,2, *}$ \\ A. BOUGIATIOTI \\ N. MIHALOPOULOS ${ }^{1}$
}

\author{
${ }^{1}$ Environmental Chemical Processes Laboratory, \\ Department of Chemistry, University of Crete, \\ P.O.Box 2208, Voutes 71003 Heraklion, Greece \\ ${ }^{2}$ Laboratory of Analytical Chemistry, Department of Chemistry, \\ Faculty of Chemistry, Al.I Cuza University of Iasi, \\ Carol I 11, 700506-lasi, Romania
}

Received: $10 / 09 / 08$

Accepted: 09/02/09 *to whom all correspondence should be addressed: e-mail: carsene@uaic.ro

\section{ABSTRACT}

The volume mixing ratios of non-methane hydrocarbons including saturated, unsaturated and aromatic ones $\left(\mathrm{C}_{2}\right.$ to $\mathrm{C}_{8}$ as non methane hydrocarbons, NMHC $\left.\mathrm{C}_{\mathrm{S}}\right)$ were measured at three distinct sites (natural, rural, urban) in the lower troposphere of the Eastern Mediterranean from February 2006 to March 2007. Average concentrations for most of the NMHC show clear seasonal variations along the year mainly attributed to photochemistry. Significant correlations found among various hydrocarbons indicate contribution from mobile and stationary sources (exhaust and combustion). Leakages from natural gas (NG) or liquefied petroleum gas (LPG) probably from the continental platforms may account for important sources for the background concentration of ethane and propane in the area. Isoprene has been found to have mostly a biogenic source but its dual anthropogenic-biogenic origin was also evident at the rural site.

KEYWORDS: Non-methane hydrocarbons, variability, sources, eastern Mediterranean.

\section{INTRODUCTION}

Most of the atmospheric trace gases and aerosols are pollutants with strong impacts on global climate, air quality and human health. Transport, meteorological dispersion, photochemical processing and physical removal determine their distribution and fate in the atmosphere. Short- and long-term measurements of atmospheric trace gases and aerosols, through direct observations, model analysis, or a combination of these techniques, have lead to advances in the understanding of their fate processes and also of their interactions. Knowledge of ambient levels of most of the atmospheric trace gases and aerosols is necessary to evolve proper strategies to control tropospheric radicals build up and to maintain healthy air quality.

Particular attention is given to the presence of specific trace gases in the atmosphere as most of them might contribute to the generation of both fine aerosol and photochemical oxidants such as ozone (Atkinson, 2000). Aerosols and ozone have direct effects on human health through respiratory inflammation, on climate change through modification of direct and indirect radiative budgets and on regional ecosystems through oxidation and changes in nutrient balance (Andreae and Crutzen, 1997).

Nowadays it is being recognised that volatile organic compounds (VOCs), sometimes referred to as non methane hydrocarbons (NMHCs) or non methane volatile organic compounds (NMVOCs), are found throughout the earth's atmosphere, emitted from a vast array of sources both man-made and naturally occurring. 
$\mathrm{NMHC}_{S}$ are low molecular weight compounds containing as elements only carbon and hydrogen, with carbon atoms from 2 up to 12. The presence of some NMHCs in air can result toxicity in the atmosphere. For example, benzene, 1,3-butadiene, formaldehyde, acetaldehyde and poly-cyclic organic matter (POM) are toxic compounds, and in the United States their release into the atmosphere is regulated by the U.S. Environmental Protection Agency. Poly-cyclic aromatic hydrocarbons (PAHs) are an important component of POM. Some toxic NMHCs are emitted directly to the atmosphere (e.g., benzene, 1,3-butadiene and POM) whereas others are also formed in-situ from other NMHCs by chemical reactions (e.g., formaldehyde and acetaldehyde).

Atmospheric hydrocarbon may contribute to particulate matter formation via semi-volatile reaction products that undergo gas-to-particle conversion. Atmospheric particles with diameter less than $2.5 \mu \mathrm{m}$ are most often produced via chemical transformations, rather than being emitted directly. Highly oxidised VOCs reaction products can nucleate and condense to form organic aerosols. Secondary Organic Aerosols (SOA) is generally only formed from the oxidation of hydrocarbons with high number of carbon atoms. Formation of SOA from isoprene is reported in the literature (Claeys et al., 2004). The products of monoterpene oxidation are comparatively non-volatile and may therefore play an important role in aerosol formation, hence affecting climate change. However, mainly, aromatics and substituted aromatics have been shown to form aerosols. It is also proposed that the concentrations of monoterpenes, combined with $\mathrm{NO}_{x}$ concentrations and the long atmospheric lifetimes of their reaction products will lead to significant yields of aerosols in specific areas. However, information on the main Secondary Organic Aerosols (SOA) precursors concentrations, for example hydrocarbons, in ambient air specific for different areas is lacking and limited information is available on their spatial and temporal variability or even more this information does not exist.

In the atmosphere, hydrocarbons originate from a wide variety of anthropogenic (automobile exhaust, combustion plant, electricity producing, solvent makers) and natural sources (biogenic or oceanic emission). In highly polluted urban areas, nonmethane VOCs typically consist of alkanes $\sim 40-45 \%$, alkenes $\sim 10 \%$, aromatic hydrocarbons $\sim 20 \%$ and oxygenates $\sim 10-15 \%$ (Harrison, 1999). Biogenic emissions are mainly in the form of isoprene and terpenes (limonene, a,b-pinenes) which beside other anthropogenic emitted hydrocarbons are assigned as important precursors of secondary organic aerosols (SOA) with important climatic role (Hoffmann et al., 1997, Odum et al., 1997).

While biogenic sources emit large quantities of VOCs, man made activities are responsible for the emission in the atmosphere of a great number of species including alkanes, alkenes, oxygenated and aromatic compounds. It has been suggested that on a worldwide basis biogenic NMVOC emissions are estimated to be a factor of almost 10 higher than the anthropogenic ones. However in urban areas anthropogenic NMHCs often dominate. There is also still a large uncertainty about the exact amount of biogenic NMHCs emissions and recent measurements have suggested that their emissions are much higher than previously estimated, necessitating re-evaluation of their global inventories (Atkinson and Arey, 1998; Atkinson and Arey, 2003).

The major sink processes for the $\mathrm{NMHC}_{s}$ are their reactions with the hydroxyl $(\mathrm{OH})$ and nitrate $\left(\mathrm{NO}_{3}\right)$ radicals but reaction with ozone is also an important sink especially for alkenes (Atkinson and Arey 2003). It is also recognised that halogen atom reactions may be an important $\mathrm{NMHC}_{\mathrm{S}}$ sink in certain areas such as in the Arctic troposphere during springtime (Hopkins et al., 2002), Antarctic boundary layer (Read et al., 2007) and some coastal regions (Arsene et al., 2007).

The seasonal distribution for most of the $\mathrm{NMHC}_{S}$ is mainly governed by their fast reaction toward oxidants such as $\mathrm{OH}$ radicals which abundance in the atmosphere is highly dependent on the amount of light and the $\mathrm{NO}_{\mathrm{x}}$ levels. Hydrocarbons abundance is fairly well mixed in Europe over the winter time when $\mathrm{NMHC}_{\mathrm{S}}$ mixing ratios are much higher than during summer time (Hakola et al., 2006).

Due to their high potential to act as ozone precursors many $\mathrm{NMHC}_{\mathrm{S}}$ are regulated as criteria pollutants (EPA Report, 2004) and some of the hydrocarbons emitted in the atmosphere can 
have harmful effects on human health and the environment (butadiene, benzene, toluene are regarded as carcinogenic and mutagenic high potential compounds) (WHO Report 91, 2000). Actually, many hydrocarbons may lead to ozone production via their reaction with $\mathrm{OH}$ radicals in the presence of sufficient levels of nitrogen oxides. At least $30 \mathrm{NMHC}_{\mathrm{S}}$ (saturated, unsaturated or aromatics) are recommended for measurements by the new Ozone Directive 2002/3/EC which has been in force from 9 September 2003. However, in 2004 measurement of $\mathrm{NMHC}_{\mathrm{S}}$ from only 14 European sites were reported to the Chemical Coordinating Centre (CCC) of the Cooperative Programme for Monitoring and Evaluation of the Long-range Transmission of Air Pollutants in Europe (EMEP), and 10 of these included also measurements for carbonylic compounds EMEP/CCC Report 8, 2006.

Presently, within Europe, networks for different pollutants sampling and analysis exist in order to find answers to purposes required by today societal needs. However yet, they do not yield sufficient information useful to quantify and attribute their effects on health, weather, and climate over all Europe. Also Chemistry Transport Models (CTMs), which attempt to describe the effects of various atmospheric species on radiation and chemical processes within the atmosphere, have been developed, but these need to be validated by real observations and presently, a suitable set of observational data does not exist.

In the present work we have combined measurements of about $45 \mathrm{C}_{2}-\mathrm{C}_{8}$ hydrocarbons in ambient air at three different environmental sites in the north-eastern Mediterranean (natural, rural and urban) where such measurements are really scarce and thus needed to understand the sources and variability of NMHCs as well as for model validation. We report also results of the variability-lifetime analysis, which along with other complementary data contribute to a better understanding of the sources of the $\mathrm{NMHC}_{\mathrm{S}}$ at the investigated sites.

\section{EXPERIMENTAL}

Hourly samples of $900 \mathrm{ml}$ of ambient air were collected and analysed within intensive measurement campaigns of several days performed each month between February 2006 and February 2007, at Crete, in the north-eastern Mediterranean. Details of the complete analytical procedure used for the $\mathrm{NMHC}_{\mathrm{S}}$ analysis (with the help of a gas chromatograph equipped with an FID detector) are presented in Arsene et al. (2007).

In situ measurements of $\mathrm{C}_{2}$ to $\mathrm{C}_{8} \mathrm{NMHC}_{\mathrm{S}}$ were conducted at three locations on the island of Crete, i.e. at the remote background monitoring station of the University of Crete (Finokalia, July - August 2006, assigned as a natural site), the new University campus (HeraklionVoutes, March 2006 - February 2007, rural area) and the former University campus (Heraklion-Knossos, February 2006, urban background site). The monitoring site at Finokalia is a remote background air monitoring station located about $70 \mathrm{~km}$ eastward of Heraklion. The new University campus is located about $15 \mathrm{~km}$ westward to the main city of Crete, Heraklion, meanwhile the former campus is more representative for a real urban background site as it is located $4 \mathrm{~km}$ eastward to the city centre of Heraklion (Koulouri et al., 2008). The new University campus is located up-wind of the main city emissions directly exposed to the sea. At the rural site, measurements of hydrocarbons were performed on a monthly basis during periods (3-5 days) of similar meteorological conditions regarding wind speed and direction (wind speed higher than $5 \mathrm{~m} \mathrm{~s}^{-1}$ and prevalent wind directions from the northern sector to identify the role of the long-range transport process).

The dataset obtained at each of the investigated area include a number of 320 samples for the rural site, 50 samples for the urban background and 140 for the natural background site.

\section{RESULTS AND DISCUSSION}

\subsection{General characteristics of the NMHC mixing ratio patterns}

Figure 1 presents the distribution in the average values of $\mathrm{NMHC}_{\mathrm{s}}$ measured in the present work at the natural, rural and urban sites in the north-eastern Mediterranean, Crete (alkanes, 1a; alkenes, 1b; dienes, acetylene and aromatic compounds, 1c).

In Figure 1 the presented values for the full range of hydrocarbons measured during different campaigns are given along with their standard deviation ( \pm standard deviation, $\pm \sigma$ ). For the rural site the values are reported through the daily summer and winter concentrations and the seasons are defined as follow, winter from October to March and summer from April to September. 

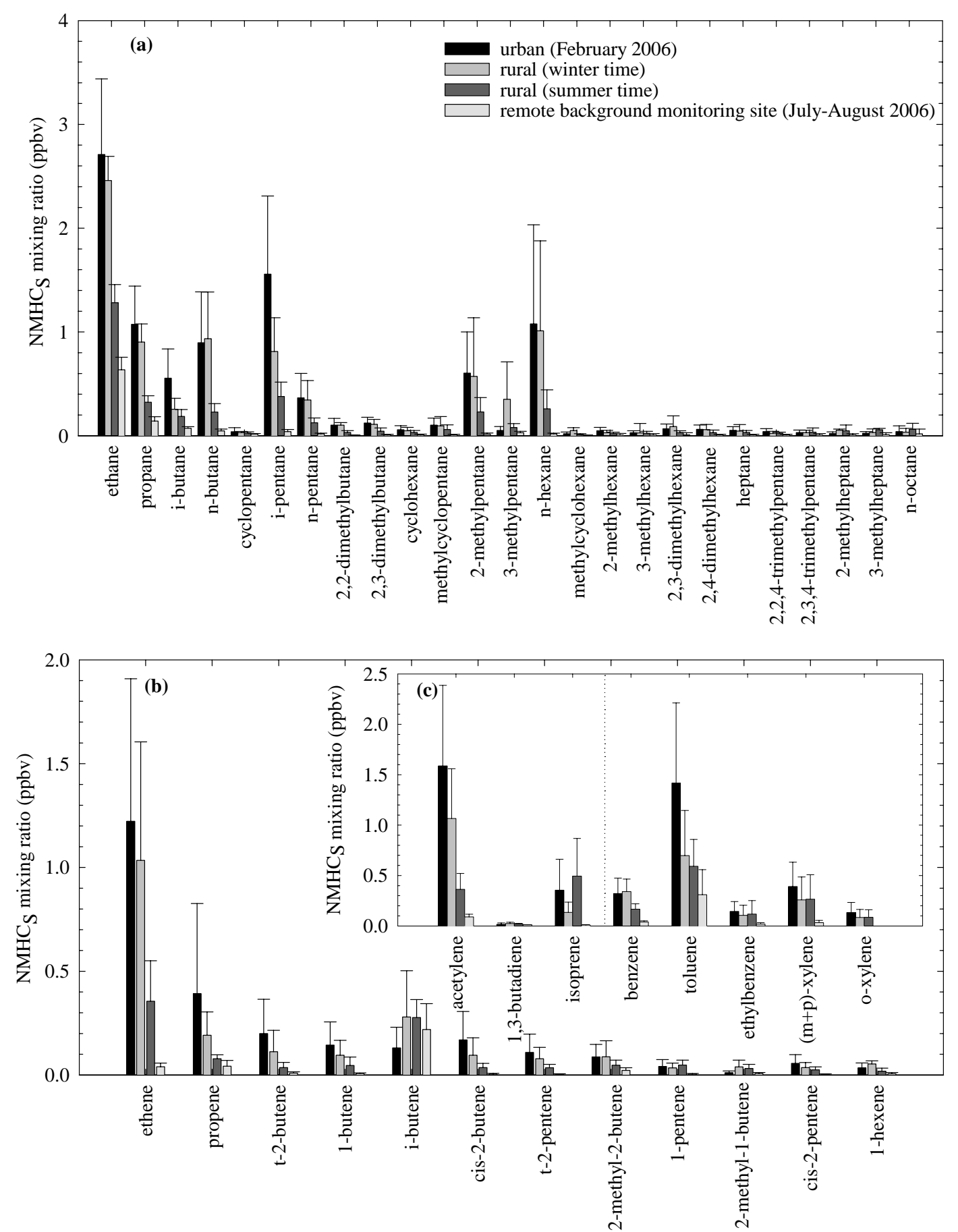

Figure 1. Average concentrations of various hydrocarbons (alkanes (1a), alkenes (1b), acetylene, dienes, and aromatics (1c)) measured in the north-eastern Mediterranean at three different locations (natural, rural and urban)

Figure 1 shows that ethane, propane, n-butane, i-pentane, n-hexane, ethene, acetylene and toluene are among the most abundant hydrocarbons at each of the investigated sites. Moreover, the distribution of the average values of measured $\mathrm{NMHC}_{s}$ follow a pattern expected from the locations of the sampling sites in respect to the pollution influence, with mixing ratios at urban > rural > natural (remote background monitoring site). Indeed average values of the $\mathrm{NMHC}_{S}$ mixing ratios measured at the urban site in February 2006 (50 samples) were higher than their average values measured in February 2007 at the rural site, and those measured at the rural site during summer 2006 were higher than those measured at the natural one during the same period. 
The NMHCs mixing ratios obtained in the present study (given as mean and median) are comparable to those reported for other sites whenever referred to urban or rural background monitoring sites (Gross et al., 2003, Hopkins et al., 2005, Plass-Dulmer et al., 2002).

Figure 2 presents the monthly variability of selected $\mathrm{NMHC}_{\mathrm{s}}$, measured from February 2006 to March 2007 at the rural site. Clear seasonal variability has been identified for almost all $\mathrm{NMHC}_{s}$, with distinct maxima (ethane, propane, i- and n-butane, $\mathrm{i}$ - and n-pentane, ethene, propene, acetylene) during the cold season, due to the reduced photochemistry and increased emission especially from fuel consumption during this season. Isoprene was the only exception as it maximises during summer due to increased natural emissions.

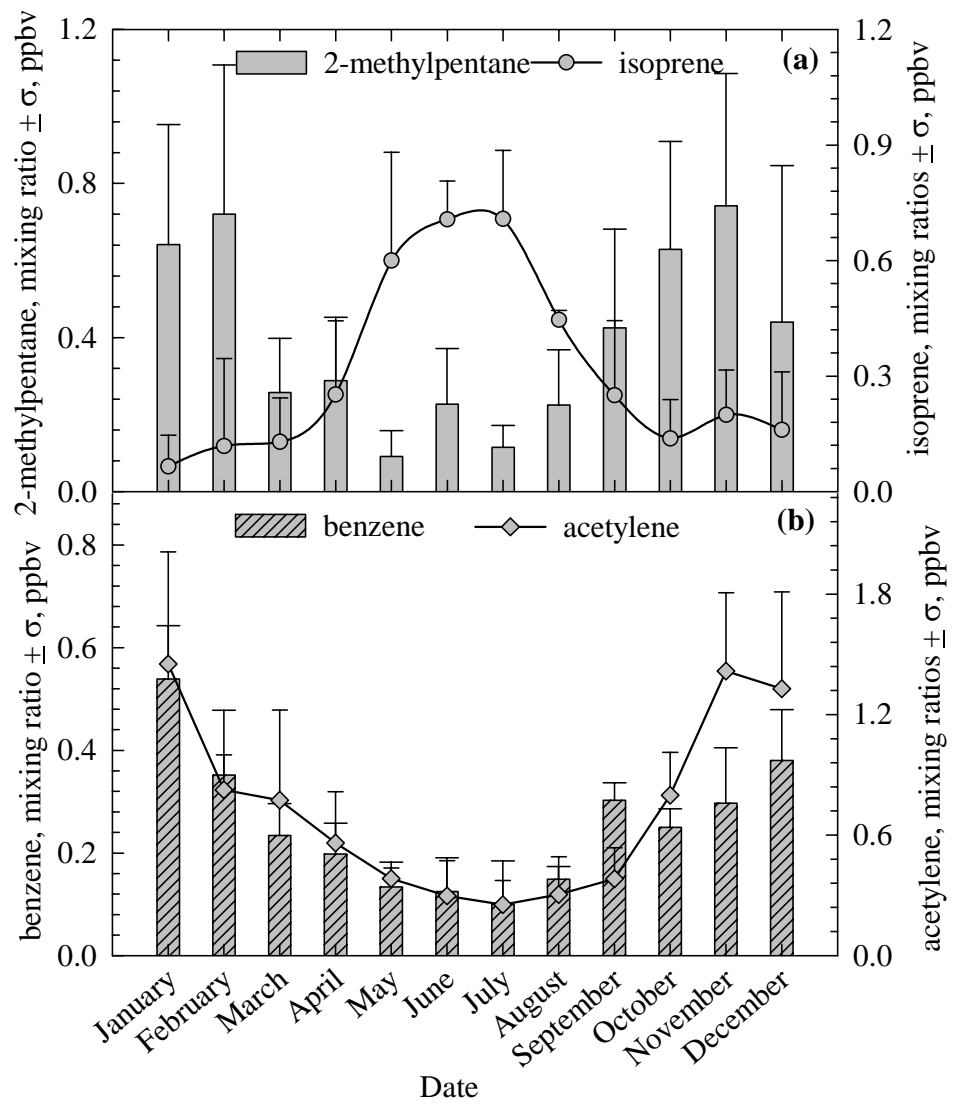

Figure 2. Monthly variability of selected hydrocarbons measured at a rural site from March 2006 to March 2007

\subsection{Source contribution}

To investigate possible source composition, correlation coefficients between various pairs of hydrocarbons have been investigated using factor analysis with extracted principal component after normalized Varimax rotation. After applying Varimax rotation, loading factors greater than 1.00 were considered as significant in the interpretation of the obtained results. The results obtained from the PCA analysis of the data measured at the natural, rural and the urban sites are included in Table 1.

About $74 \%$ of the total variance is explained for both the rural and the urban sites meanwhile for the natural site only $50 \%$ accounts for the total variance. Moreover for the rural and urban sites there are five main extracted factors meanwhile at the natural site only two factors can be considered. In each factor significant number of hydrocarbons have loadings greater than 0.7 .

At the rural and at the urban sites the first factor (F1), which accounts for $30.9 \%$ of the total variance, shows high loadings for components characterising contributions from combustion and stationary sources (e.g. acetylene, n-butane, t-2-butene, 1-butene, cis-2-butene, ipentane, n-pentane, t-2-pentene, cis-2-pentene). 
Table 1. Factor loadings after Varimax rotation normalized applied to the data set at the rural site

\begin{tabular}{|c|c|c|c|c|c|c|c|}
\hline Location & Rura & Urban & & & & Natur & \\
\hline Factor & F1 & F2 & F3 & F4 & F5 & $\mathrm{F} 1^{*}$ & $\mathrm{~F} 2^{*}$ \\
\hline $\begin{array}{l}\text { Variance } \\
(\%)\end{array}$ & 30.9 & 14.4 & 12.5 & 5.7 & 10.3 & 32.6 & 17.5 \\
\hline ethane & 0.22 & 0.08 & 0.19 & 0.02 & 0.87 & 0.72 & 0.44 \\
\hline ethene & 0.32 & 0.16 & 0.74 & -0.16 & 0.47 & 0.79 & 0.02 \\
\hline propane & 0.31 & 0.07 & 0.19 & 0.01 & 0.87 & 0.85 & 0.14 \\
\hline propene & 0.33 & 0.19 & 0.74 & -0.11 & 0.38 & 0.56 & 0.04 \\
\hline acetylene & 0.90 & 0.14 & 0.12 & -0.04 & 0.25 & 0.91 & 0.15 \\
\hline i-butane & 0.20 & 0.03 & 0.76 & 0.09 & 0.12 & 0.77 & 0.43 \\
\hline n-butane & 0.79 & 0.16 & 0.16 & -0.11 & 0.44 & 0.86 & 0.03 \\
\hline t-2-butene & 0.91 & 0.09 & 0.24 & 0.11 & 0.15 & 0.52 & 0.08 \\
\hline 1-butene & 0.78 & 0.37 & 0.28 & 0.05 & 0.27 & 0.36 & 0.47 \\
\hline i-butene & 0.12 & 0.80 & -0.24 & 0.05 & -0.08 & -0.01 & 0.91 \\
\hline c-2-butene & 0.92 & 0.11 & 0.21 & 0.09 & 0.16 & 0.22 & 0.18 \\
\hline cyclopentane & 0.59 & 0.08 & 0.33 & 0.34 & 0.09 & 0.67 & 0.50 \\
\hline i-pentane & 0.91 & 0.15 & 0.25 & 0.00 & 0.17 & 0.80 & 0.09 \\
\hline n-pentane & 0.72 & 0.24 & 0.16 & 0.22 & 0.31 & 0.89 & 0.09 \\
\hline 1,3-butadiene & 0.36 & 0.36 & 0.21 & 0.08 & 0.35 & 0.57 & 0.43 \\
\hline $\mathrm{t}$-2-pentene & 0.83 & 0.20 & 0.31 & 0.14 & 0.07 & 0.36 & 0.19 \\
\hline 2-methyl-2-butene & 0.51 & 0.69 & -0.04 & 0.17 & 0.21 & 0.11 & 0.85 \\
\hline 1-pentene & 0.49 & 0.31 & 0.12 & -0.11 & -0.28 & 0.34 & 0.02 \\
\hline 2-methyl-1-butene & 0.69 & 0.37 & -0.17 & -0.08 & 0.20 & -0.03 & 0.84 \\
\hline c-2-pentene & 0.84 & 0.19 & 0.31 & 0.14 & 0.03 & 0.33 & 0.09 \\
\hline cyclohexane & 0.47 & 0.19 & 0.61 & 0.06 & 0.10 & 0.14 & 0.20 \\
\hline 2-methyl-pentane & 0.58 & 0.14 & 0.27 & 0.28 & 0.23 & 0.77 & 0.06 \\
\hline 3-meyhyl-pentane & 0.02 & 0.16 & 0.22 & -0.28 & -0.06 & -0.05 & 0.33 \\
\hline n-hexane & 0.22 & 0.34 & -0.07 & 0.71 & 0.07 & 0.40 & 0.47 \\
\hline isoprene & 0.08 & -0.04 & 0.13 & 0.83 & -0.12 & 0.20 & 0.74 \\
\hline benzene & 0.40 & 0.22 & 0.54 & -0.06 & 0.50 & 0.72 & 0.37 \\
\hline toluene & 0.25 & 0.49 & 0.41 & 0.10 & -0.02 & 0.28 & 0.21 \\
\hline ethyl-benzene & 0.14 & 0.85 & 0.30 & 0.01 & 0.15 & - & - \\
\hline$(m+p)$-xylene & 0.21 & 0.73 & 0.45 & -0.08 & 0.13 & 0.50 & 0.26 \\
\hline o-xylene & 0.21 & 0.80 & 0.33 & -0.02 & 0.16 & - & - \\
\hline
\end{tabular}

A second factor (F2) explaining $14.4 \%$ of the total variance corresponds to hydrocarbons emitted mainly from fuel consumption (vehicle exhaust). It includes i-butene, ethyl-benzene, $(m+p)-x y l e n e$ and o-xylene. The third factor with a $12.5 \%$ contribution to the total variance includes hydrocarbons from surface evaporative emissions related to solvent use in various industrial activities around the site (ethene, propene, i-butane).

The fourth factor (F4) explaining only $5.7 \%$ of the total variance characterises mainly the contribution from the biogenic sources with very high loading factor for isoprene (0.83). Unexpected and presently not yet understood is the presence of n-hexane in the same factor (hexane is used in various industrial processes as a solvent, i.e. in coatings, paints, and adhesives). However, this case may suggest the dual nature source of isoprene which is suspected to be also of anthropogenic origin.

The last factor (F5), with a contribution in variance of $10.3 \%$, underlines the presence of ethane and propane which would imply definitely a common source most probable from natural gasses (NG) and liquefied petroleum gas (LPG) leakages from the continental platform. Benzene shows significant loadings within F1, F3 and F5 which would suggest that its ambient level may come from a variety of sources and not only from the automotive exhaust. 
At the natural site the extracted factors correspond actually to the anthropogenic ( $\mathrm{F} 1^{*}$ with a $32.6 \%$ contribution to the total variance) and biogenic (F2 with $17.5 \%$ contribution) in source origin fractions.

The first factor comprises most of the hydrocarbons of anthropogenic origin (ethane, propane, $\mathrm{i}$ - and $\mathrm{n}$-butanes and pentanes, acetylene, ethene, propene, 1,3-butadiene, benzene) meanwhile the second factor is mainly related to hydrocarbons of biogenic origin. This factor includes i-butene, 2-methyl-1-butene, 2-methyl-2-butene and isoprene. Apart isoprene, which is considered of biogenic origin, i-butene is also suspected of marine origin (Bonsang, private communication). This hypothesis is confirmed by the mean (median) of i-butene at each of the investigated sites (all coastal locations) which have relatively high values. In the present work at each investigated site, although assigned as natural, rural and urban, the values for $\mathrm{i}-$ butene are much higher (>0.2 ppbv) compared with those reported by Hopkins et al. (2005) of $0.1 \mathrm{ppbv}$ or Plass-Dulmer (2002) of $0.012 \mathrm{ppbv}$ at other continental urban or rural sites.

\section{CONCLUSIONS}

The present work provides an assessment of individual hydrocarbon sources on a spatial and temporal basis in a study performed in the Eastern Mediterranean. High quality continuous hourly NMHC data sets are used to characterise their sources especially at urban and rural scale. In order to explore accurately the behaviour of the identified hydrocarbons (related to their sources), the concentrations of the measured hydrocarbons were followed with high temporal resolution in different intensive campaigns.

Hydrocarbons as ethane, ethene, propane, propene, n-butane, iso-butene, 1-butene, trans-2butene, cis-2-butene, 1,3-butadiene, n-pentane, isopentane, 1-pentene, 2-pentene, isoprene, $\mathrm{n}$-hexane, isohexane, $\mathrm{n}$-heptane, n-octane, iso-octane, benzene, toluene, ethyl-benzene, $(m+p)$-xylene, o-xylene and 1,2,4-(1,2,3-; 1,3,5-)-trimethyl-benzene, which are among the most important ozone precursor hydrocarbons, were measured in the present work.

Measurements of $\mathrm{C}_{2}$ to $\mathrm{C}_{8} \mathrm{NMHC}_{\mathrm{S}}$ (45 compounds) were performed on the island of Crete in the Eastern Mediterranean at three distinct locations (natural, rural and urban) from February 2006 to March 2007. As the measurements were performed during periods of similar meteorological conditions regarding wind speed and direction (northern prevalent wind sector sometime with influences from the western coastal line of the island) it was possible to distinguish between the role of long-range transport process and contributions from local sources. Most of the measured hydrocarbons present clear seasonal variability with minimum during high insolation period of a year (photochemistry responsible).

Contribution from various sources may account for the abundance of the measured hydrocarbons at the monitored sites. Ethane and propane are associated with natural gas (NG) and liquefied petroleum gas (LPG) leakages from the continental platform, especially due to their long atmospheric residence time. Other identified sources include vehicle exhaust, stationary combustion and biogenic emission. Benzene ambient levels may arise at the investigated sites from a variety of sources and not only from the automotive exhaust meanwhile isoprene, expected mainly as of biogenic source, may have a dual nature in its origin involving also an anthropogenic fraction.

\section{ACKNOWLEDGEMENTS}

This project has been supported by the Greek-Romanian bilateral project supported by General Secretary of Research and Technology (Greece) and Romanian Ministry of Science. AB acknowledges support from GSRT through PENED 2003 grant.

\section{REFERENCES}

Andreae M.O. and Crutzen P.J. (1997), Atmospheric aerosols: Biogeochemical sources and role in atmospheric chemistry, Science, 276, 1052-1058.

Arsene C., Bougiatioti A., Kanakidou M., Bonsang B. and Mihalopoulos N. (2007), Tropospheric $\mathrm{OH}$ and $\mathrm{Cl}$ levels deduced from non-methane hydrocarbon measurements in a marine site, Atmospheric Chemistry and Physics Discussion, 7, 6329-6356. 
Atkinson R. (2000), Atmospheric chemistry of VOCs and $\mathrm{NO}_{\mathrm{x}}$, Atmospheric Environment, 34, 2063-2101.

Atkinson R. and Arey J. (1998), Atmospheric chemistry of biogenic organic compounds. Accounts Chemical Research, 31, 574-583.

Atkinson R. and Arey J. (2003), Atmospheric degradation of volatile organic compounds, Chemical Reviews, 103, 4605-4638.

Claeys M., Wang W., Ion A.C., Kourtchev I., Gelencser A. and Maenhaut W. (2004), Formation of secondary organic aerosols from isoprene and its gas-phase oxidation products through reaction with hydrogen peroxide, Atmospheric Environment, 38, 4093-4098.

EMEP/CCC Report 8, VOC measurements 2004 (2006), Solberg, S., accessed March 2007, URL: http://www.nilu.no/projects/ccc/reports/cccr8-2006.doc.

EPA Report (2004), Air toxics website: List of hazardous air pollutants, accessed March 2007, URL: http://www.epa.gov/ttn/atw/188 polls.html.

Gross V., Williams J., Van Aardenne J.A., Salisbury G., Hofmann R., Lawrence M.G., Von Kuhlmann R., Lelieveld J., Krol M., Berresheim H., Lobert J.M. and Atlas E. (2003), Origin of anthropogenic hydrocarbons and halocarbons measured in the summertime European outflow (on Crete 2001), Atmospheric Chemistry and Physics, 3, 1223-1235.

Hakola $\mathrm{H}$., Hellen $\mathrm{H}$. and Laurila T. (2006), Ten years of light hydrocarbons $\left(\mathrm{C}_{2}-\mathrm{C}_{6}\right)$ concentration measurements in background air in Finland, Atmospheric Environment, 40, 3621-3630.

Harrison, D. (1999), Development and validation of systems for the analysis of atmospheric hydrocarbons. University of Leeds, UK.

Hoffmann T., Odum J.R., Bowman F., Collins D., Klockow D., Flagan R.C. and Seinfeld J.H. (1997), Formation of organic aerosols from the oxidation of biogenic hydrocarbons, Journal of Atmospheric Chemistry, 26, 189-222.

Hopkins J.R., Jones I.D., Lewis A.C., McQuid J.B. and Seakins P.W. (2002), Non-methane hydrocarbons in the Arctic boundary layer, Atmospheric Environment, 36, 3217-3229.

Hopkins J.R., Lewis A.C. and Seakins P.W. (2005), Analysis and applications of measurements of source dominated hydrocarbon concentrations from the PUMA campaigns in June/July 1999 and January/February 2000 at an urban background site in Birmingham, UK, Atmospheric Environment, 39, 535-548.

Koulouri E, Grivas G., Gerasopoulos E., Chaloulakou A., Mihalopoulos N., Spyrellis N., (2008), Study of size-segregated particle (PM1, PM2.5, PM10) concentrations over Greece, Global Nest Journal, 10 (2): 132-139.

Odum J.R., Jungkamp T.P.W., Griffin R.J., Flagan R.C. and Seinfeld J.H. (1997), The atmospheric aerosol-forming potential of while gasoline vapour, Science, 276, 96-99.

Plass-Dulmer C., Michl K., Ruf R. and Berresheim H. (2002), $\mathrm{C}_{2}-\mathrm{C}_{8}$ hydrocarbon measurement and quality control procedures at the Global Atmosphere Watch Observatory Hohenpeissnberg, Journal of Chromatography A, 953, 175-197.

Read K.A., Lewis A.C., Salmon R.A., Jones A. and Bauguitte S. (2007), OH and halogen atom influence on the variability of non-methane hydrocarbons in the Antarctic Boundary Layer, Tellus, 59, 22-38.

WHO Report 91 (2000), Air quality guidelines for Europe, Organic pollutants, World Health Organisation, Regional Office for Europe, Copenhagen, accessed in March 2007, URL: http://www.euro.who.int/document/e71922.pdf. 